\title{
SAÚDE DO HOMEM: UM ESTUDO REALIZADO NA UNIDADE DE SAÚDE DA PEDREIRA EM BELÉM, PARÁ
}

\author{
Dorotéa Albuquerque de Cristo, Solange Conceição Albuquerque de Cristo
}

\section{RESUMO}

Justificativa: Este artigo é resultado de pesquisa que investigou como homens avaliam o serviço da atenção primária de um bairro em Belém, suas concepções de autocuidado e as motivações para aderirem a esse serviço que objetiva a prevenção de doenças e promoção da saúde. Através de suas percepções pode-se chegar também aos motivos das ausências da maioria dos homens na Atenção Primária. Pelas estatísticas do Ministério da Saúde, os homens adentram a saúde pela alta e pela média complexidade, quando doenças e agravos já estão instalados.

Método: 0 estudo é qualitativo, de natureza fenomenológica, considerando a relação sujeito e mundo, e foi realizado com 10 homens, na faixa etária de 19 a 59 anos, usuários de uma unidade básica de saúde (UBS), atendidos no setor da clínica. As categorias de análise foram: importância da Atenção Primária para sua saúde, atendimento prestado na Unidade de Saúde da Pedreira, suas necessidades de saúde e práticas de autocuidado. Outros fatores relevantes no contexto do estudo foram: relações com o trabalho e com a família.

Resultados: Os resultados mostraram que os motivos da adesão são sinais e sintomas de doenças e agravos e recomendação de atendimento na UBS por parte de terceiros. Vários sentidos foram captados: receio, responsabilização, vergonha e irritabilidade por estarem doentes. Ter que esperar, ter que abrir mão do que percebem como prazeroso, dentro de um universo de situações adversas.

Conclusões: $O$ estudo apontou que os usuários da UBS Pedreira não se percebem como invulneráveis, temem as doenças e não frequentam espaços de saúde para não vivenciarem a dor, como se a doença passasse a ter existência real a partir de sua presença nos serviços, com isso evitam procurar ajuda, mesmo diante de sintomas. Como o espaço privilegia as medidas curativas, e não a promoção de saúde, os homens continuam afastados do serviço.

Palavras-chave: homens; saúde; atenção primária; autocuidado; fenomenologia.

Revista da Rede APS 2019 Publicada em: $24 / 07 / 2019$

DOI:10.14295/aps.v1i2.25

Dorotéa Albuquerque de Cristo (Universidade da Amazônia e Secretaria de Estado de Saúde Pública do Pará, Brasil); Solange Conceição Albuquerque de Cristo (Universidade Federal do Sul e Sudeste do Pará, Brasil);

Correspondência para: Dorotéa Albuquerque de Cristo, dcristo@bol.com.br 


\section{INTRODUÇÃO}

A Política Nacional de Atenção Integral à Saúde do Homem, criada em 2008 pelo Ministério da Saúde, é uma estratégia para minimizar a ausência dos homens na atenção primária. De acordo com vários estudos que ajudaram a formular a política, os homens são mais vulneráveis às enfermidades, principalmente às crônicas e graves, e morrem mais cedo que as mulheres. Não possuem o hábito de acessar o serviço de atenção primária e geralmente adentram a saúde pelos serviços de média e de alta complexidade. Retardam a atenção à saúde e, consequentemente, contribuem para o agravamento do quadro de doença, limitando a ação apenas ao atendimento e não à prevenção e à promoção da saúde.

$\mathrm{Na}$ realidade brasileira, a população masculina apresenta índices de mortalidade mais elevados em comparação à população feminina. As causas de óbito entre os homens se devem a fatores externos (acidentes, lesões autoprovocadas e agressões), seguidos de doenças do aparelho circulatório e tumores, doenças do aparelho digestivo e do aparelho respiratório, muitas causas evitáveis e que estão diretamente ligadas a um estilo de vida. Percebe-se também que os fatores externos se constituem um grande problema de saúde pública com forte impacto nos índices de mortalidade na população masculina (Política de Atenção Integral à Saúde do Homem, 2008).

No Pará, os índices de mortalidade, de acordo com o Departamento de Informática (DATASUS) do Ministério da Saúde (2013), são os seguintes: o número total de óbitos foi de 9.482 em 2012, sendo 5.326 casos de homens e 4.156 de mulheres. Quanto a Belém, os números foram um total de 4.910 óbitos, sendo 2.599 de casos de homens e 2.311 de mulheres. A mortalidade entre os homens é maior.

A preocupação com o bem-estar dos homens sem questionar a autonomia e o protagonismo do sujeito contraria os princípios do SUS e sem isso não teremos como exigir a corresponsabilidade dele por sua saúde, já que sua participação direta está excluída do debate.
De acordo com Figueiredo (2005), estudos apontam as instituições de saúde como reprodutoras do imaginário social de gênero, com repercussões na atenção oferecida à comunidade. De acordo com o autor, os serviços de saúde oferecem um tempo menor de seus profissionais aos homens quando em comparação com as mulheres. Partindo-se da organização e rotina dos serviços, percebe-se uma disposição do espaço voltado ao público feminino, segmento que, por anos, foi prioridade absoluta. Os cartazes afixados nas unidades sempre expressam campanhas de aleitamento materno, pré-natal, exames preventivos do colo do útero e mama, dentre outros. É inegável a importância das campanhas na redução da mortalidade da mulher e da criança, porém, pouco se percebe sobre campanhas voltadas ao público masculino. Esse espaço pode também causar no público masculino uma sensação de não pertencimento.

No caso da unidade objeto da pesquisa, conforme os dados estatísticos do serviço, em novembro de 2013 o total de usuários atendidos foi de 1.827, sendo 660 homens apenas, incluindo os idosos, e 1.167 mulheres.

Diante do exposto, a busca por respostas no próprio homem foi a questão central que norteou a pesquisa, num estudo que procura abarcar tanto suas concepções do atendimento na unidade de saúde como os significados que atribui ao autocuidado. Essas percepções permitiram averiguar as motivações dos homens para empreenderem o cuidado à sua saúde.

\section{MÉTODO}

A pesquisa é qualitativa, considerando a relação entre o sujeito e o mundo. Para Grisotti e Patrício (2006), esse estudo responde a questões sociais envolvendo o sujeito diretamente no processo, investigando fenômenos de grupos humanos com seus significados, crenças, valores, sentimentos e práticas.

Foi utilizada como referencial metodológico a fenomenologia-hermenêutica de Paul Ricouer, que utiliza a linguagem e o símbolo para compreender o sujeito (Terra, Gonçalves, Santos \& Erdmann, 2009). 
Paul Ricouer (1913-2005) considerou a dimensão histórico-cultural e relacionou o ser à linguagem e às condições de sua existência no mundo. Em Ricouer não se concebe o acesso imediato à consciência, já que é necessário passar pela interpretação dos significados para chegar ao conhecimento da consciência e do ser. É preciso compreender os vários significados de mundo do sujeito e de sua cultura para dar sentido à sua existência. Esse acesso se dá pela linguagem, que é específica para cada grupo. A narrativa permite ao sujeito refletir sobre o tempo e a história, dando-lhe significado. Desenvolve nova perspectiva de subjetividade, relacionada à linguagem, à interpretação, à ação, à narração e à história social, revelando a dimensão histórica do ser (Sodré, 2008).

Para explicar a relação privilegiada da hermenêutica com a linguagem e com o texto, é necessário que se lembre de uma questão comum nas línguas que exige interpretação, que é a polissemia. A polissemia é um caráter presente nas línguas naturais, que é o traço de as palavras deterem mais de um significado quando se consideram fora de seu uso em determinado contexto (Ricouer, 1990). Considerar o contexto exige outra tarefa que é exercida na troca de mensagens entre os interlocutores, usando como modelo o jogo de perguntas e respostas. Essa tarefa é a interpretação.

\section{Público-alvo}

No percurso teórico-metodológico desta pesquisa toma-se, como campo de investigação empírica, uma unidade básica de saúde no centro de Belém do Pará e o estudo documental. No campo de estudos documentais, realizou-se o exame de leis que tratam da Política Nacional de Saúde do Ministério da Saúde e a literatura científica sobre violência, masculinidades, cuidado com a saúde e os prontuários da unidade básica.

O processo de aproximação com o campo até a finalização da pesquisa durou 12 meses. A entrada no campo teve seu começo em março de 2013, quando foi dado início ao conhecimento do serviço por meio de diálogos informais com servidores e gestores, assim como foi feito o reconhecimento do local e de sua dinâmica.

O estudo foi efetuado com 10 homens usuários da unidade básica de saúde que manifestaram espontaneamente desejo de participar da pesquisa, sendo garantido o anonimato. O número de participantes demarca o delineamento qualitativo que busca alcançar uma compreensão em profundidade dos sujeitos.

Os critérios para inclusão dos informantes foram faixa etária de 19 a 59 anos (faixa etária adulta) e que estivessem se consultado na clínica, já que esse setor configura o cuidado mais preventivo com a saúde, diferente dos setores de especialidades, como psiquiatria, ou do setor de urgência e emergência. Os critérios de exclusão foram homens que frequentaram os demais setores da unidade de saúde, não desejaram participar da pesquisa ou estavam fora do intervalo etário.

Por se tratar de pesquisa com seres humanos, os sujeitos assinaram Termo de Consentimento Livre e Esclarecido, de acordo com os aspectos éticos instituídos na Resolução №196/96, versão 2012, do Conselho Nacional de Saúde. O protocolo de pesquisa foi aprovado pelo Comitê de Ética de Pesquisa com Seres Humanos da Universidade Federal do Pará, sob o no 351.815. O local de coleta de dados foi na própria unidade básica, numa sala de atendimentos, por ser um ambiente familiar aos sujeitos, onde eles puderam se sentir à vontade.

Foi utilizada a entrevista semiestruturada, com perguntas norteadoras em que os entrevistados discorreram livremente sobre algumas questões, mas, no decorrer da entrevista, outras surgiram, objetivando explicar o entendimento.

As entrevistas foram gravadas para que se pudesse captar a realidade vivida por meio da fala e da escuta sensível das falas. Esse contexto da entrevista foi fundamental, pois nessa metodologia a observação das ações acompanha a entrevista: silêncios, risos, movimentos, etc. que traduzem o modo que os informantes apreendem a temática refletida, bem como a função de linguagem emotiva que os informantes destacaram. Para preservar o anonimato dos participantes, as falas dos 
entrevistados foram identificadas por meio de nomes fictícios.

\section{RESULTADOS E DISCUSSÃO}

Entende-se que a presença do homem na UBS se dá em função do seu estado atual, com alguma enfermidade, já que antes não buscavam, não viam necessidade e possuíam hábitos que, de acordo com seus discursos, podem ter contribuído para o quadro de sua doença:

"Cuidados? A gente não se cuida muito, não procura médico mesmo. Procurei agora, mas não procuro." (José, 48 anos).

A importância da UBS para esses usuários está ligada à assistência, a necessidade do serviço surge com sua necessidade de atendimento médico: "Bem, pra mim posto é para tratar doença, não é não? Antes eu não precisava, agora preciso." (Francisco, 54 anos). Veem no médico a única figura responsável pela saúde das pessoas.

Nas diversas respostas às questões sobre a importância da atenção primária para a saúde, as questões de gênero se destacaram. Não procuram se cuidar, nem fazem prevenção, mas parecem acreditar que é assim mesmo com todos os homens, que só procuram assistência em último caso.

Percebem suas necessidades voltadas apenas aos cuidados médicos de que necessitam para a cura da doença que apresentam. Doenças geralmente relacionadas aos hábitos de vida, ao consumo excessivo de álcool e fumo, o que faz com que se sintam responsáveis diante dos problemas. Os Usuários temem por seu estado, temem possíveis danos provocados pelas doenças, inclusive a morte, citada em algumas falas:

"Tenho medo de morrer assim, de repente! Mas me disseram que meu caso não é urgente" (João, 52 anos);

"Não gosto de hospital, nem de médico, eles lembram doença, morte" (José, 48 anos);

"O homem é muito machista, não procura a saúde, morre muito de câncer o homem" (Matias, 44 anos);
"Mas meu pai morreu de câncer e também era gordo como eu" (Marcos, 24 anos).

Nas narrativas dos usuários aparecem falas que expressam dificuldades em seguir recomendações médicas. Como forma de amenizar seus problemas, seguem apenas parcialmente as orientações:

"Ela cortou no ano passado a bebida, o pão, o açúcar. Cortei um pouco. Ela disse [médica]: 'Se comer dois pães, só come um. Açúcar, põe só uma colherzinha. Bebida, tu corta mesmo!', cortei a bebida e o cigarro." (Matias, 44 anos).

Os usuários da UBS narram que, apesar de reconhecerem seus hábitos de vida como prejudiciais, os percebem também como prazerosos, os raros prazeres que possuem:

"Ah! Eu deveria fazer dieta, o nutricionista passou, mas ainda não consigo. Engordei demais, é isso, mas como muita farinha, gordura, a gente não aprende mesmo! Bebo, mas não é muito não. A minha cervejinha eu não paro. Se tirar isso é meu fim mesmo!" (Luís, 43 anos).

A percepção dos usuários sobre dificuldades no autocuidado envolve também outras categorias, como a relação com o trabalho e com a família. $\mathrm{Na}$ maioria dos discursos, as responsabilidades com a família são percebidas mais como obrigações legais, sujeitas a sanções e reprovação social, do que vínculo afetivo:

"Tem os filhos, tem a pensão deles..." (Luís, 43 anos)

"Tenho três filhas, a mais velha, de 14 anos já está grávida e ainda vou ter que sustentar ela e o bebê! $\mathrm{Na}$ verdade senhora, não tenho tempo de ficar doente, quem vai sustentar a casa?" (Pedro, 46 anos).

Quanto ao trabalho, consideram as adversidades envolvendo o estresse e a pouca satisfação que o emprego proporciona, além da periculosidade de alguns deles:

"Sou vigilante noturno, então fico muito preocupado, aqui está muito violento. Acho que esse trabalho me faz mal, por isso fiquei doente, mas tenho que trabalhar mesmo" (João, 52 anos); 
"Eu trabalho com química, carrego vela, produtos da vela, como motorista. Minha profissão são várias, na minha carteira tá como vendedor, mas trabalho mais como motorista. Acho que também por isso que fiquei doente" (Matias, 44 anos).

\section{Reflexões Finais}

Nas respostas às questões, vários sentidos foram captados: receio, responsabilização, vergonha e irritabilidade por estarem doentes. Ter que esperar, ter que abrir mão do que percebem como prazeroso, dentro de um universo de situações adversas (trabalhos vistos como estressantes, salários insuficientes para suas necessidades, bairros perigosos, atendimentos precários, problemas familiares). Não há trabalhos preventivos na comunidade e ainda existe a dificuldade de acesso e assistência nas demais unidades básicas de saúde de outros bairros. Não se sentem livres para fazer suas escolhas e não conseguem perceber outras possibilidades dentro desse contexto.

De acordo com estudos que subsidiaram a política, a não presença dos homens nos espaços de APS decorre de variáveis culturais, em que a doença significa fragilidade e o homem considera-se invulnerável, expondo-se mais a situações de risco e cuidando menos de si. Em parte, este estudo corrobora essa afirmação, porém, deve-se considerar que, para que se possa corresponsabilizar o homem pelas decisões sobre sua saúde, o sistema deve contribuir para ampliar o grau de autonomia desses homens, como preconiza o SUS.

Sem fomentar o protagonismo, apenas responsabilizando o homem por sua doença e exigindo dele uma posição passiva diante do fenômeno, em que deve seguir ordens médicas para não morrer, isso resultará em sujeitos tutelados, dependentes de um benefício da previdência, usuários que não têm condições de se responsabilizarem pela própria vida.

De acordo com Campos e Campos (2009), autonomia é um processo de coconstituição de maior capacidade do sujeito de compreender e agir sobre si mesmo e sobre o contexto. Para que se chegue a esse resultado, os profissionais devem favorecer o acesso dos sujeitos à informação, para que possam utilizar esse conhecimento em exercício crítico, com capacidade de agir sobre o mundo, de interferir sobre sua rede de dependências. $O$ que se percebe no contexto da UBS em estudo são homens que não conseguem estabelecer compromissos consigo mesmos e com os outros para criar bem-estar e transformar o contexto, mesmo conhecendo sua necessidade.

A situação exige um trabalho preventivo que atenda a demanda dos homens nesses espaços, sem essa ação não tem como parar o processo gradual e alarmante que se instalou, pois ele não muda de direção repentinamente. A estratégia incluiria, também, atrair o maior número de homens ao serviço com atividades de promoção de saúde (programas de saúde que envolvem saúde de grupos, famílias e comunidade). Os usuários ouvidos nesta pesquisa desconheciam o papel da UBS na comunidade e chegaram ao serviço por indicação ou levados por terceiros após a instalação dos sintomas.

Dos 10 usuários participantes, 7 apresentam quadros de doenças crônicas, apontadas nas pesquisas como uma das principais causas de morte de homens no mundo, muitas delas passíveis de prevenção, se fossem feitas intervenções em práticas que contribuíram para a ocorrência desses problemas (Figueiredo, 2005; Brasil, 2008).

Os usuários não falaram das relações com as suas companheiras como relevantes para seu adoecimento, percebem-nas apenas como cuidadoras. Isso nos faz considerar, preliminarmente, que as relações afetivas, dentro desse contexto de adoecimento e sentimento de vulnerabilidade, produzem novas reflexões que nos permitem entender os significados para esses homens, pois os problemas no relacionamento ficam reduzidos e quase imperceptíveis diante dessa nova experiência. As relações conjugais parecem ser ressignificadas e vistas apenas como um benefício.

Ainda precisamos considerar que, assim como indicado nas pesquisas do Ministério da Saúde 
(2008), o cuidado é papel feminino, então eles identificam suas companheiras como responsáveis pelos cuidados, inclusive deles: "Cheguei pra minha companheira e falei: 'Estou muito cansado'. Ela marcou e vim pra cá!" (Matias, 44 anos); "Minha mulher me trouxe, sentia muita dor de cabeça. Ela marcou a consulta e tirou uma ficha, então, eu vim!" (João, 52 anos).

De acordo com a análise dos discursos dos usuários da UBS Pedreira, pode-se constatar o uso de uma linguagem verbal que denota haver uma aproximação e um afastamento de si, ilustrada nas falas "o homem", "eu", "a gente". Falam ao mesmo tempo como espectadores e como sujeitos da ação. Com essa linguagem expressam que se sentem parte de um coletivo, que os demais homens, assim como eles, possuem as mesmas características. Dessa forma; também parecem se distanciar de si mesmos, por exemplo, "os homens são assim mesmo" e "isso é da cultura masculina".

Apesar de os homens estarem mais expostos a riscos, o estudo apontou que os usuários da UBS Pedreira não se percebem como invulneráveis, temem as doenças e não frequentam espaços de saúde para não vivenciarem a dor, como se a doença passasse a ter existência real a partir de sua presença nos serviços, com isso evitam procurar ajuda, mesmo diante de sintomas. Como o espaço privilegia as medidas curativas, e não a promoção de saúde, os homens continuam afastados do serviço.

Portanto, dentre as ações essenciais para o avanço da política, de acordo com a pesquisa, apontam-se os aspectos educacionais e outras ações organizadas que visam ao acolhimento do homem, fazendo com que se sinta parte integrante da APS, respeitando suas peculiaridades culturais.

\section{REFERÊNCIAS BIBLIOGRÁFICAS}

(1) Aquino, E.M.L. (2006). Gênero e saúde: perfil e tendências da produção científica no Brasil. Rev. Saúde Pública. Vol. 40. (N. Esp.). (pp.121-32)
(2) Brasil. Ministério da Saúde. (2008). Política Nacional de Atenção integral à saúde do homem: princípios e diretrizes. Ministério da Saúde. Secretaria de atenção à saúde. Departamento de ações programáticas estratégicas. Brasília/ DF

(3) Brasil. Ministério da Saúde. (2011). Portaria 2488/GM, de 21 de outubro de 2011. Política nacional de atenção básica. Diário Oficial da União, Brasília, DF, 24/10/2011, Seção 1, (pp.48-55)

(4) Brasil. Ministério da Saúde. (2011a). Vigitel Brasil 2010. Vigilância de fatores de risco e proteção para doenças crônicas por inquérito telefônico. Ministério da Saúde, Secretaria de Vigilância em Saúde, Secretaria de Gestão Estratégica e Participativa. Brasília: Ministério da Saúde. 152 p.

(5) Brasil. Ministério da Saúde. (2013). Departamento de Informática do Sistema Único de Saúde (DATASUS). Ministério da Saúde. Retirado em 18 de outubro de 2013, de http://www2.datasus.gov.br/DATASUS/index.php?a cao $=11 \& i d=31430$

(6) Campos, G. W. S. \& Campos, R. T.O. (2009). Coconstrução de autonomia: o sujeito em questão. In Campos, G.W.S., Minayo, M.C.S, Akerman, M., Drumond, M., Jr. \& Carvalho, Y. M. (orgs.). Tratado de saúde coletiva. São Paulo: HUCITEC; Rio de Janeiro: FIOCRUZ. (pp. 669-679)

(7) Figueiredo, W. (2005). Assistência à saúde dos homens: um desafio para os serviços de atenção primária. Ciênc. saúde coletiva [online]. Vol. X (n.1), (pp. 105-109)

(8) Frei Betto, (2003). Desigualdade social no Brasil. Retirado em 10 de março de 2013, de http://amaivos.uol.com.br/amaivos09/noticia/notic ia.asp?cod_Canal=53\&c od_noticia $=15576$

(9) Giraldi, R. (2013). Homens jovens e pobres são os principais suspeitos e vítimas dos homicídios. Agência Brasil. retirado em 10 de março de 2013, de http://agenciabrasil.ebc.com.br/noticia/2013-0302/homens-jovens-epobres-sao-os-principaissuspeitos-e-vitimas-dos-homicidios

(10) Grisotti, M., Patrício, Z.M. (2006). A saúde coletiva entre discursos e práticas: a participação de 


\section{APS em Revista}

Vol. 1, n. 2, p. 162/169 | Maio/Agosto - 2019

ISSN 2596-3317 - DOI 10.14295/aps.v1i2.25

Cristo, D. A; Cristo, S. C. A.

usuários, trabalhadores e conselheiros de saúde no município de Florianopólis. Florianópoilis: UFSC, $159 p$

(11) Perissinotto, R.M. (2004). Hannah Arendt, poder e a crítica da "tradição". Luanova, no 61. (pp.115138)

(12) Ricouer, P. (1990) Interpretação e Ideologias (4a ed.). RJ: Ed. Francisco Alves

(13) Sodré, O. (2008). Abordagem histórico-cultural da subjetividade. Belo Horizonte: UFMG; Ribeirão Preto: USP, (pp. 88 a 99)

(14) Ribeiro, M.C.S.A., Barata, R.B. (2012). Condições de saúde da população brasileira. In Giovanella, L., Escorel, S., Lobato, L.V.C., Noronha, J.C., Carvalho, A.I. (orgs.) (2012). Políticas e sistema de saúde no
Brasil (pp ). 2a ed. rev. e ampl. Rio de Janeiro: FIOCRUZ. 1.100p.

(15) Senkevics, A. (2012). Desigualdade de gênero. Ensaios de Gênero. Retirado em10 de março de 2013, de http://ensaiosdegenero.wordpress.com/tag/desigu aldade-de-genero/

(16) Souza, E. R. (2005) Masculinidade e violência no Brasil: contribuições para a reflexão no campo da saúde. Ciência \& Saúde coletiva, 10 (1) (pp.59-70)

(17) Terra, M.G., Gonçalves, L.H.T., Santos, E.K.A. \& Erdmann A.L. (2009). Fenomenologia-hermenêutica de Paul Ricoeur como referencial metodológico numa pesquisa de ensino em enfermagem. Acta paul. enferm. São Paulo. Vol. XXII (no1). 


\section{ABSTRACT}

Background: This article is the result of research that investigated how men evaluate the Primary Care service of a neighborhood in Belém, its conceptions of self care and the motivations to adhere to this service that aims to prevent diseases and promote health. According to Ministry of Health statistics, men enter health through high and medium complexities, when diseases and injuries are already installed. The results showed that the reasons for adherence are signs and symptoms of diseases and injuries, and recommendation of care in the BHU by third parties.

Methods: The study is qualitative, of a phenomenological nature, considering the subject and world relationship, and was carried out with 10 men, in the aged group between 19 to 59 years, users of a basic health unit (BHU), attended in the clinic sector. The categories of analysis were: importance of primary care to the health, attendance provided at the Pedreira Health Unit, your health needs and self-care practices. Other relevant factors in the context of the study were: relationships with work and family.

Results: The results showed that the reasons for the adherence are signs and symptoms of diseases and injuries, and recommendation of attendance in the BHU by part from thirds. Several senses were obtained: fear, responsibilization, shame and irritability for they being sick. Have to wait, having to give up what they perceive as pleasurable, within a universe of adverse situations.

Conclusions: The study pointed out that the users of BHU Pedreira do not perceive themselves as invulnerable, they fear the diseases and they do not frequent health spaces to they not experience the pain, as if the disease only would pass to have real existence starting from their presence in the services, with that they avoid to search help, even in front of the symptoms. Since space privileges curative measures, and not health promotion, the men remain away from services.

Keywords: men; health; primary care; self-care; phenomenology. 